\title{
Blood Transfusion Development within the Next 10 Years
}

\author{
Pr. Philippe Rouger
}

Institut National de la Transfusion Sanguine, INSERM (Institut National de la Santé et de la Recherche Médicale) U 665, Université Pierre et Marie Curie-Paris6, France

\section{Key Words}

Blood transfusion - Blood safety · New blood products Transfusion medicine

\section{Summary}

Within the next 10 years it is most unlikely for a major discovery to significantly transform the necessity of calling for red blood cells, platelets and plasma as a substitute treatment for the human population. Blood products are 'doomed' to a human origin, ever, the same way as calling for human blood donation is forever to stay. Consequently, practice development and improvement has to be constantly enhanced for an ever increasing quality and efficiency treatment to be provided to the patient. This article describes such critical items subject to progress, such as donation, self-sufficiency, medical practice, quality assurance, risk management, regulations, socio-economic aspects, biotechnologies, research and training.

\section{Introduction}

Developments in blood transfusion can only be envisaged in comparison with drug evolution. Within the next 10 years, what will be the evolution of medical practices, the environment of pathology and ageing, the effectiveness of medications including grafts and blood transfusions using new substitutes?

Medical practices will move towards less and less invasive methods using an ever decreasing quantity of blood products in surgical operations. Requirements should remain stable in

\section{Schlüsselwörter}

Bluttransfusion · Blutsicherheit · Neue Blutprodukte

Transfusionsmedizin

\section{Zusammenfassung}

Innerhalb der kommenden 10 Jahre ist es sehr unwahrscheinlich, dass eine bahnbrechende Entdeckung die Notwendigkeit der Verwendung von Erythrozyten, Thrombozyten und Blutplasma für die Substitutionsbehandlung beim Menschen verändern wird. Blutprodukte werden immer menschlichen Ursprungs sein, ebenso wie es immer einen Aufruf zur Blutspende geben wird. Folgerichtig ist auch die praktische Durchführung ständig verbessert worden, um für die Patienten eine qualitativ und effektiv immer bessere Behandlung zu gewährleisten. Der vorliegende Artikel beschreibt Aspekte, die Ziel dieser fortschreitenden Verbesserung sind: Blutspende, Selbstversorgung, medizinische Praxis, Qualitätssicherung, Risikomanagement, Richtlinien, sozioökonomische Aspekte, Biotechnologien, Forschung und Mitarbeitertraining.

the hematology field. Medical requirements should progress for patients over 70 years of age. The European heterogeneity should gradually disappear in favor of practices founded on evidence based medicine.

Pathology and ageing environment: In less than 30 years, life expectation for men has increased by 10 years on average. That is why transfusional requirements such as the ageing-associated pathologies are necessarily increasing. As yet, no recognized European survey assessing this new situation has been published.

\section{KARGER \\ (C) 2006 S. Karger GmbH, Freiburg


Nevertheless, it is clear that, for each considered country, ageing will impact the increase in blood product consumption, particularly in Northern Europe.

Effectiveness of medications, including grafts: While biotechnology has opened the horizon to new medications, it is most probable that the next 10 years (2005-2014) will appear differently from the past decade. The pharmaceutical industry is more investing in the improved use of already identified and developed molecules than in the discovery of innovative agents. Grafts, just like transfusions, are facing a constant evolution issue, partially linked to donations.

As a matter of fact, no anticipated sign of a revolution has come up so far in the fundamental research, and a great deal of studies have still to be conducted in the genomic research field.

Blood substitutes: Research in this field started more than 40 years ago, but so far no fully validated substitute for red blood cells or platelets has been found, which clinical trials would have entitled to serve in the medical use. In spite of developments in chemistry (e.g. perfluorocarbon) and genetic recombination (e.g. genetically recombined hemoglobin), there has been no significant progress in terms of validated clinical usage. Thus, we are led to think that no actual red blood cell substitute as oxygen transporter or within the complex platelet functions will ever be found.

All these analyses bring us to the fundamental conclusion regarding the future, sounding like 'people will still need human blood in the 10 years ahead.'

Ten subjects for thought may be considered as follows [1].

\section{Donor Ethics with Regard to Self-Sufficiency}

In the 10 years to come, European self-sufficiency will be a constant concern, both for cellular products and for plasma, the lack of which is already of great importance. European and worldwide requirements will probably increase considerably. Such contexts give rise to market-related methods, detrimental to the ethical approach. A respectful attitude to donors must be safeguarded even though altruism tends to become a 'naïve value' as opposed to the pragmatism involved to fulfil public health requirements.

With no vigilance observed, the number of remunerated donors might increase at the expense of the non-profit ethic safety. Blood transfusion in Europe would then move to some kind of a 'blood business', burning fingers first, then hand and arm to end up with the extinction of human values!

That is why it is so important for the European Commission, the European Parliament and all Member States to proceed for keeping up the balance and respecting the fundamental blood transfusion values [2].

\section{The Approach of the Donor Faced with Technological Developments}

The approach to 'blood' and 'blood donations' varies from one country to another, from daily altruism to the pragmatic facing of facts. This heterogeneity is faced with galloping mechanization and computerization in many blood-collecting methods. Blood collection technologies will develop considerably to achieve a direct line between the donation and the usable finished product.

This technological development will have at least three corollaries: quantification, standardization and safety. There are still many pending questions with no clear answer; for example, what is the future for multiple and simultaneous collections? Will they turn out to become the norm [3]?

In this context, it is plain to see that anything in favor of a circuit and procedure simplification would be adding value on the way to self-sufficiency.

\section{Controlling Labile Blood Products: From Collection to Transfusion}

The preparation of labile blood products already benefits from a pharmaceutical-type treatment that must be developed in years to come, along with all necessary measures to ensure quality. Nevertheless, product specificity will remain the same as long as it comes from a donor or from a limited number of donors.

Product development will lead us to look again at the parameters concerning the ageing of cells and methods for preserving them by establishing new ratios between the length of preservation and the functionality of cellular products. Further clinical trials should be undertaken that include the new parameters concerning recent products. Are we relying on outdated figures? Could Europe give us an opportunity to organize such initiatives?

Finished products will be more and more limited to the donor, but it may possibly be given ex vivo treatments for the safest use of blood (inactivation of pathogens, pegilation, enzymatic treatments, lyophilization, molecular enriching, etc.). Industrial partnerships should be developed [4].

Because of an increased centralization, the quality of products and procedures (up to the recipient) will undergo logistic controls of growing importance. Interaction between blood transfusion establishments and hospitals (or clinics) will have to be redefined in terms of safety.

\section{Transfusional Biology: From Product Qualification to Recipients' Safety}

Transfusional biology will be submitted to both following imperatives: measures allowing to rapidly carry out analyses and 
favoring the development of automated analysis modules. Methods will associate immunology and molecular biology and may rely on immunomolecular hybrids, combining the advantages of both approaches: sensitivity, specificity, early detection and diversity of analysis.

Technologies will undergo many developments using a variety of amplification systems, amplified detection and nanotechnologies. Such developments will bring to light a wider range of infectious agents and a full understanding of polymorphic genetic markers [5].

They will also benefit from donation qualifications and studies on the recipient's characteristics. This whole work package will be associated to information technology (IT) and data system improvements.

\section{The Need for Blood Products in Medical Practice}

The future usually grows from today's experience. Where prescription and blood product use are concerned, there is a huge disparity between the different countries in the EU. In this context, the first step consists in analyzing and finding out why. It is up to transfusion in Europe to give the answers and up to each country to act in consequence.

Such consequences will vary according to the development of the transfusional system, to the instigation, and to the involvement of the EU Member States.

In clinical matters, the next 10 years will make it possible to redefine the criteria for product efficacy (using 2005-2014 standards) and take into account hemovigilance results, both descriptive and preventive, at a local and European level.

Key idea is to always bear in mind that human blood is rare and precious and should be used advisedly, without excess and with discernment, for the correct treatment of patients $[5]$.

\section{Quality Assurance and Risk Management}

In the future, blood transfusion will be based on the quality assurance concept where the right balance must be found between pharmaceutical functioning and medicine. It should be indeed reminded that its epicenter and product responsibility are shifting to an ever larger industrial sphere. This move towards general quality standards will apply all over the transfusional field and the transfusional chain, in particular at the interface level [6].

Risk management will induce two types of approach: The first will consist in issuing reports on all secondary incidents and accidents during transfusions, knowing perfectly how to define such objectives as pharmacovigilance and hemovigilance. The second will depend on watchdogs (e.g. for transmissible agents) and reference centers (particularly in the blood group field).

\section{References and a European Regulation}

The EU development is a great luck for each country that can now position itself in relationship with its other partners and according to the references that will soon be established. The national level will have to be reconciled with the European dimension.

The European Directive 2002/98/EC anticipates the initiation of committees ([1], chapter 9, articles 28,29 and 30) to be in charge of the regulation application and follow-up.

The major problem with such committees is that they tend more to reflect the administration than the medical profession. That is why it is necessary for blood transfusion practitioners to keep on fighting in favor of the human being and blood transfusion medical values. Here lies one of the objectives of the EuroNet-TMS network via the learned societies and their 7,500 members.

With the European Commission comes the development of 'cross-functional' actions in all blood transfusion areas (such as the BOTIA (Blood and Organ Transmissible Infectious Agents) project) for the development of safety in blood transfusion [7].

\section{The Socio-Economic Development of Blood Transfusion}

The future should allow for an unruffled approach to the cost of blood products and the overall economy of the transfusion business. Even at the core of EuroNet-TMS, it is impossible to avoid this aspect in so far as it conditions blood transfusion developments. When it is well known that the same product costs 2.5 times more from one EU country to another, a complete transparency has to be adopted to analyze and understand pricing calculations.

While it is possible to identify cost-inflating measures (leukodepletion type, NAT, etc.), does this mean such measures are taken into account at the correct price? This is one among other aspects to be clarified by the European blood transfusion. In fact, the European society demands full transparency and truth for the donors and the whole population as it has been stipulated in the latest adoption of the treaties. However, with each situation being different from another, price comparisons should not become a standardization symbol [1].

\section{Blood Biotechnologies, Biotherapies and Research}

On a European scale, the strategy of innovation should be founded on a number of guidelines:

- Substitutes for blood components, taking into account the current status and the problems connected, to a large degree, to the physiology of blood components and their regulation system. 
- Recombinant proteins and rearranged proteins should be developed further in spite of this field being now limited because of the progress noted concerning recombinant proteins implicated in hemostasis (factor VII, factor VIII, factor IX, etc.). There is another generation of monoclonal antibodies thanks to genomic rearrangements. It will also facilitate the prevention of hemolytic disease of the newborn.

- Ex vivo production of red blood cells has been possible for a number of years, but the essential stages still need to be validated: the analytic content of the products as well as the functionality and physiology of the cells must be validated by clinical trials on a European scale before starting the industrial production.

- Cellular therapies: Cell use and manipulation remains a field in which the application has overtaken fundamental research developments. The fundamental knowledge must be mastered before developing applications to treat diseases affecting a large population. Each medical discipline will take its place according to its specificity and inherent issues. On the other hand, blood transfusion establishments could play an outstanding part in the operational techniques, by deploying their knowledge in the field of cellular biology.
- Fundamental and applied research in polymorphism and infectious agents.

In every approach it is necessary to develop transparent strategies with a direct link to the public health realities and in partnership with the industry.

Nevertheless, as blood product knowledge and safety have remarkably changed in the last 10 years, we have to adopt a pragmatic attitude, consolidate what has been gained and develop them still further [1].

\section{Training and Information Technology}

IT development is the key to efficacy in safe transfusion at every stage from the donor to recipient. A European consensual reflection would be welcome on the subject.

'Lifetime' teaching and training are the best solidity guarantees in medical activities. We also need to implement a European scale reflection in order to put the right person in the right job and to better adjust between training, qualification and professional practice. This should be sufficiently independent of the people involved to avoid any confusion with operational arrangements. That is one of EuroNet-TMS' priorities in 2005-2008 [8].

\section{References}

1 Rouger P, Hossenlopp C (eds): Blood Transfusion in Europe: The White Book 2005. Paris, Elsevier, 2005.

2 MacLachlan HV: The unpaid donation of blood and altruism: a comment on Keown. J Med Ethics 1998;24:252-4.

3 Davenport R: Blood components should be labelled for content. Transfusion 2005;45:3.

4 Goodrough L, Shander A, Brecher M: Transfusion medicine: looking to the future. Lancet 2003;361: $161-169$.
5 Schönitzer D: General data on blood organisations and activities in blood transfusion in Europe; in Rouger P, Hossenlopp C (eds): Blood Transfusion in Europe: The White Book 2005. Paris, Elsevier, 2005 pp 109-124.

6 Van der Poel CL, Janssen MP: Report on the Collection, Testing and Use of Blood Products in Europe in 2003. Strasbourg, Edition du Conseil de l'Europe, 2005.
Rouger P: Transfusion medicine in Europe. Transus Clin Biol 2004;11:11-14.

8 Muller N: Training and Education; in Rouger P, Hossenlopp C (eds): Blood Transfusion in Europe: The White Book 2005. Paris, Elsevier, 2005, pp 129-140. 